\title{
МОЛОДЕЖНЫЕ БРЕНДЫ ОДЕЖДЫ КАК АГЕНТЫ СОЦИАЛИЗАЦИИ
}

\author{
М. С. Калуга \\ Московский гуманитарный университет
}

Аннотация: В статье рассматриваются молодежные бренды одежды Н\&M, United colors of Benetton, Zara как агенты социализации; на основе качественного анализа контента социальных кампаний названных брендов выделены социальные ценности и нормы, транслируемые ими.

Ключевые слова: социализация; агент социализации; социальные ценности; социальные нормы; молодежь; бренд одежды; социальная кампания

\section{YOUTH CLOTHING BRANDS AS AGENTS OF SOCIALIZATION}

\author{
M. S. Kaluga \\ Moscow University for the Humanities
}

Abstract: The article deals with youth clothing brands H\&M, United colors of Benetton, and Zara as agents of socialization. The author highlights values and norms broadcast by them on the basis of a qualitative analysis of the content of social campaigns of these brands.

Keywords: socialization; socialization agent; social values; social norms; youth; clothing brand; social campaign

Проблематика социализации относится к наиболее разработанным темам в рамках научной школы социологии молодежи Московского гуманитарного университета. Теоретико-методологические аспекты исследования социализации молодежи представлены в трудах А. И. Ковалевой (Ковалева, $1997,1998,2000)$ и Вал. А. Лукова (Луков, 2012). Исследования различных категорий детей и молодежи на эмпирическом уровне посвящены трудовой социализации (Агранат и др., 2005), профессиональной социализации (Перинская, 2014; Селиверстова, 2017) социализации в иноэтнической среде (Селиверстова, 1993, 1994) и другим видам социализации. Мода в связи с социализацией молодежи до сих пор представителями научной школы не рассматривалась. Между тем современная молодежная мода противоречива, провокационна и даже скандальна, поэтому активно обсуждаема. Она находится в постоянном обновлении. Опираясь на новые тренды, мода регулярно транслирует новые представления о теле, отношениях между полами, поколениями, гендерных ролях, персональной идентичности и т. д. Данные характеристики и обусловили актуальность проблемы исследования молодежных брендов одежды как агентов социализации. 
Цель статьи - представить результаты анализа контента сайтов молодежных брендов, об их социальных обязательствах и социальных кампаниях. Ключевым понятием для исследования было - «социализация молодежи», которое используется в следующем толковании: это двусторонний процесс (1) постоянной передачи обществом и (2) освоения индивидом, по возрасту относящимся к молодежи, социальных норм, культурных ценностей и образцов поведения, позволяющего молодому человеку функционировать в данном обществе (Ковалева: Электр. ресурс). Автор статьи сфокусировался на трансляции социальных ценностей и норм молодежными брендами одежды.

Для заявленного анализа были отобраны самые крупные продавцы молодежной одежды: H\&M, United colors of Benetton, Zara. Критерии отбора: ценовая политика, fashion-коллекции, социальные обязательства и социальные кампании, рекламные кампании FW18. Эти бренды относятся к производителям со средней ценовой политикой, что обеспечивает масштаб распространения их продукции. Качественному анализу был подвергнут контент сайтов данных брендов, посвященный социальным обязательствам и социальным кампаниям, различные публикации о социальных проектах в СМИ, относящиеся к периоду 2012-2019 гг. В отдельных случаях автор привлекает к анализу материалы рекламных кампаний. Кроме того, она использовала свой опыт включенного наблюдения в качестве сотрудника компании United colors of Benetton.

В настоящее время многие компании предлагают практическое решение социальных проблем посредством реализации различных проектов и программ, напрямую транслируя определенные социальные ценности и нормы. Социальный маркетинг, как правило, не имеет отношение к получению прямой материальной выгоды, его функции в создании положительного имиджа компании и формировании лояльного отношения общества. Важнейшей целью социальных проектов является информирование потенциальных покупателей о проблеме и демонстрация солидарности бренда с ними.

Социальные кампании бренда H\&M. Одной из самых известных социальных кампаний бренда Н\&M является программа по переработке ненужной одежды Garment Collecting ${ }^{1}$. C 2013 г. компания запустила данную программу по всему миру. Основная цель программы - это всемирная инициатива создать более экологичную моду будущего. В любом магазине Н\&M можно сдать ненужные текстильные вещи любого бренда в любом состоянии и получить в обмен ваучер, позволяющий совершить покупку со скидкой

${ }^{1} \mathrm{H} \& \mathrm{M}$ [Электр. peсурс] // H\&M Group. https://hmgroup.com/sustainability.html (дата обращения 11.01.2019). 
Научные труды Московского гуманитарного университета 2019 № 5

15\%. Далее собранные изделия поступают на перерабатывающий завод, где их сортируют вручную. После сортировки одежда в хорошем состоянии, подлежащая дальнейшей носке, реализуется во всем мире как товар «секонд-хенд». Одежда и текстиль, непригодные к использованию, идут на производство новых товаров. Изделия, которые не подлежат повторному использованию, перерабатываются на текстильное волокно, применяемое для производства амортизирующих и изоляционных материалов в автомобилестроении. Доходы, полученные от сбора одежды, инвестируются в исследования, посвященные переработке текстильной продукции, а также в социальные проекты.

Данный социальный проект был поддержан в 2015 г. рекламной кампанией о важности переработки отходов. Видеоролики содержали провокационный контент о том, что можно нарушать все модные предписания, нельзя - правила переработки отходов. Позже в 2016 г. была запущена кампания WorldRecuclingWeek, цель которой была в доказательстве, что существует замкнутый цикл производства одежда, а также желание уменьшить негативное воздействие модной индустрии на окружающую среду. В этот же период бренд продолжал поддерживать имидж компании, нарушающей модные правила, но не нарушающей правила переработки отходов. В рекламе осенней коллекции были представлены нетипичные образы девушек. В видео героини рекламы ковырят вилкой в зубах, носят короткую стрижку, носят мужские вещи, сидят в метро, как мужчины, с раздвинутыми ногами. Саундтреком к видео была композиция "Sheislady", что подтвержает, что все девушки не перестают быть женственными вне зависимости от их внешнего вида и поступков, которые они совершают.

Бренд владеет фондом H\&MFoundation, который занимается финансированием иновационных подходов в области модной промышленности. С 1 сентября 2016 г. организация открыла прием заявок на участие в премии Global Change Award, которую присуждают за открытие успешных проектов, меняющих производство и переработку материалов для индустрии моды. Также особое внимание уделяется разработкам новых материалов, которые можно использовать в производстве одежды.

На протяжении 8 лет компания выпускает лимитированные линейки одежды из переработанных материалов H\&MConsciousExclusive. Одной из самых запоминающихся была коллекция 2017 года, лицом которой была модель Наталья Водянова. В данной экоколлекции одежда была создана из переработанных пластиковых отходов, собранных на берегах водоемов. Воздушное платье со струящейся плиссировкой из полиэстера BIONIC, которое модель презентовала в рекламной кампании, было изготовлено из переработанного пластика (рис. 1). По замыслу дизайнеров, это летящее 
платье символизирует естественность заботы об окружающей среде.

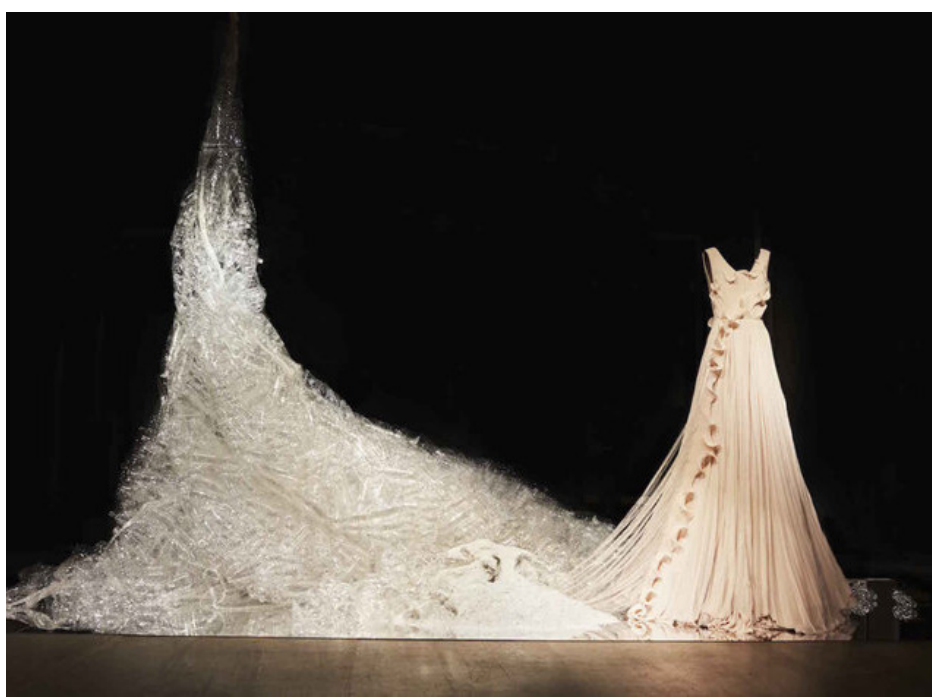

Рисунок 1. Платье, изготовленное из переработанного пластика, в коллекции H\&MConsciousExclusive 2017.

Picture 1. Dress made of recycled plastic from the H\&MConsciousExclusive 2017 collection.

В 2018 г. в капсульной коллекции была одежда, созданная из переработанного кашемира и бархата, который, в свою очередь, был создан из переработанного полиэфира. 11 апреля 2019 г. был объявлен старт продаж восьмой по счету экологичной коллекции Н\&M. При создании этой коллекции использовались 3 новых материала, полученные из экологичных источников (рис. 2).
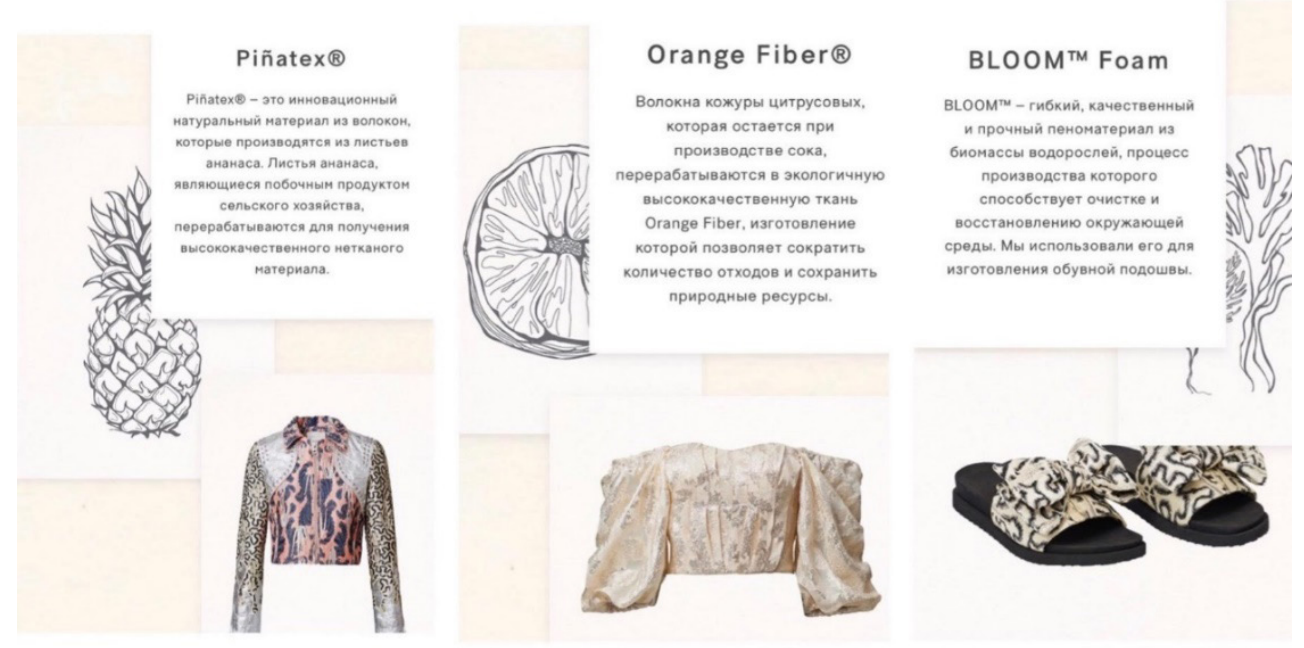

Рисунок 2. Новые материалы, используемые в коллекции H\&MConsciousExclusive 2019.

Picture 2. New fabrics used in the H\&MConsciousExclusive 2019 collection. 
Научные труды Московского гуманитарного университета 2019 № 5

Таким образом, своими социальными кампаниями, бренд Н\&М активно привлекает внимание к проблеме загрязнения окружающей среды и длительной переработки вещей, которые люди выбрасывают. Компания привлекает молодежь, своих активных потребителей, к переработке ненужной одежды и возможности дать ей “вторую жизнь”, формируя ценность сохранения окружающей среды и новые нормы экологической культуры молодежи. Одновременно, в рекламных кампаниях эта организация расшатывает устои традиционной культуры, в том числе гендерные стереотипы поведения, ориентируясь на восприимчивость молодежи, используя ее протестный потенциал.

Социальные кампании бренда United colors of Benetton. В 2012 г. бренд United colors of Benetton представил социальный проект «Безработный года», который был создан совместно с фондом UNHATE ${ }^{1}$. UNHATEFoundation это часть масштабного проекта Benetton, направленного на продвижение норм толерантности и терпимости по отношению к представителям других рас, этносов, религий, политических партий и др. Целью фонда является привлечение внимания общества к проявлениям ненависти и пропаганда терпимости.

Бренд в своей социальной кампании поднимает главную проблему Европейского союза - безработицу. В рамках данной кампании молодые безработные люди от 18 до 30 лет представляли свои проекты, которые решали отдельные социально-значимые проблемы и обеспечивали трудовую занятость молодежи, как правило, не только автора проекта. Было организовано онлайн-голосование, и 100 лучших проектов получили финансирование. Президент BenettonGroup Алессандро Бенеттон заявил, что данная кампания представляет реалистичный портрет современного общества, которое ежедневно сталкивается с общей проблемой незанятости молодежи и потенциального конфликта поколенийㄹ. Для бренда было важно подчеркнуть ценность огромного человеческого капитала, который представляет собой молодежь.

Этот проект сопровождался серией фотопортретов «Потерянного поколения» - молодых людей от 18 до 30 лет, которые не могут трудостроиться после окончания университетов, первое поколение после Второй мировой

${ }^{1}$ United Colors of Benetton: беспрецедентный проект «Безработный года» [Электронный ресурс] // Wildberries.ru. URL: https://style.wildberries.ru/united-colors-ofbenetton-bespretsedentnyiy-proekt-bezrabotnyiy-goda/ (дата обращения 03.02.2019).

${ }^{2}$ Benneton борется с безработицей [Электронный ресурс] // csrjournal.com. URL: http://csrjournal.com/5132-benetton-boretsya-s-bezraboticey-sredi-molodezhi.html (дата обращения 10.01.2019). 
войны, столкнувшееся с большими трудностями в поиске работы и планировании своего будущего (рис. 3).

\section{“Безработный года"}
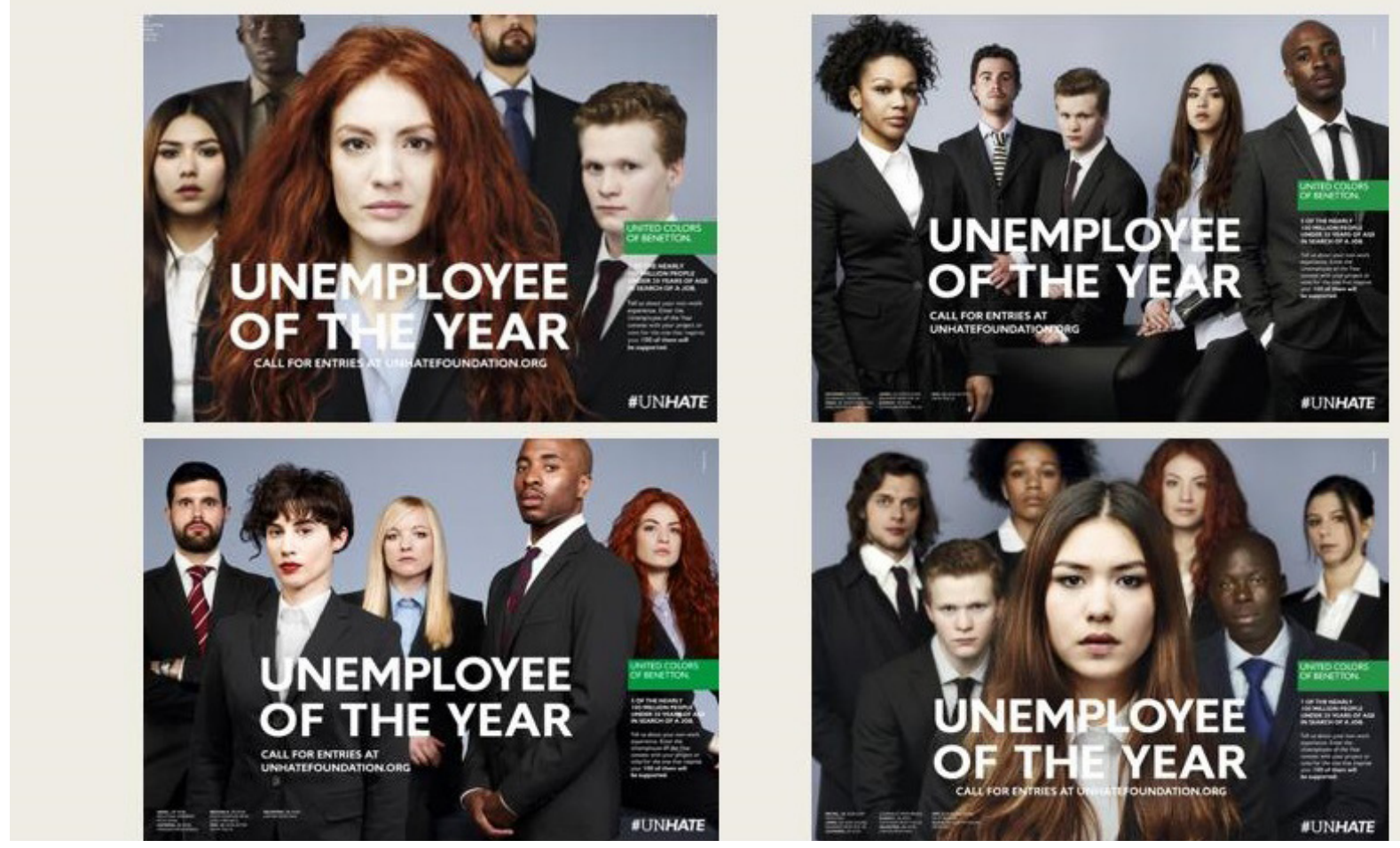

Рисунок 3. Снимки, сопровождающие сощиальную кампанию «Безработный года».

Picture 3. Photographs made for the "Unemployed of the Year" social campaign.

На фотографиях данного цикла молодые мужчины и женщины, представители разных рас, то есть проблема безработицы уравнивает всех.

В 2015 г. бренд United colors of Benetton объявил о запуске социального проекта WomenEmpowerment, направленного на поддержку прав женщин. Данный проект согласован со стратегией ООН. Программа началась с 5-летнего проекта «Достойная жизнь» (Sustainable Livelihood), предусматривающего инвестиции в размере 2 млн евро в поддержку женщин, занятых в секторе производства одежды ${ }^{1}$. Первый шаг проекта включает в себя разработку активностей, направленных на улучшение положения женщин, а именно тренинг-сессии по гендерным и другим вопросам, которые каса-

Модная Россия. Обзор новостей [Электронный ресурс] // www.modnaya. URL: http:// www.modnaya.ru/news/riamoda/2015/11-6.htm (дата обращения 11.01.2019). 
ются базовых неотчуждаемых прав, получение информации и навыков по микрокредитованию и другие мероприятия по финансовой поддержке женщин, информирование в области прав женщин, программы, разработанные для женщин, занятых в производстве, и их детей. В России покупателей информировали о целях и содержании этой программы, сопровождая процесс выбора товаров трансляцией видео-роликов.

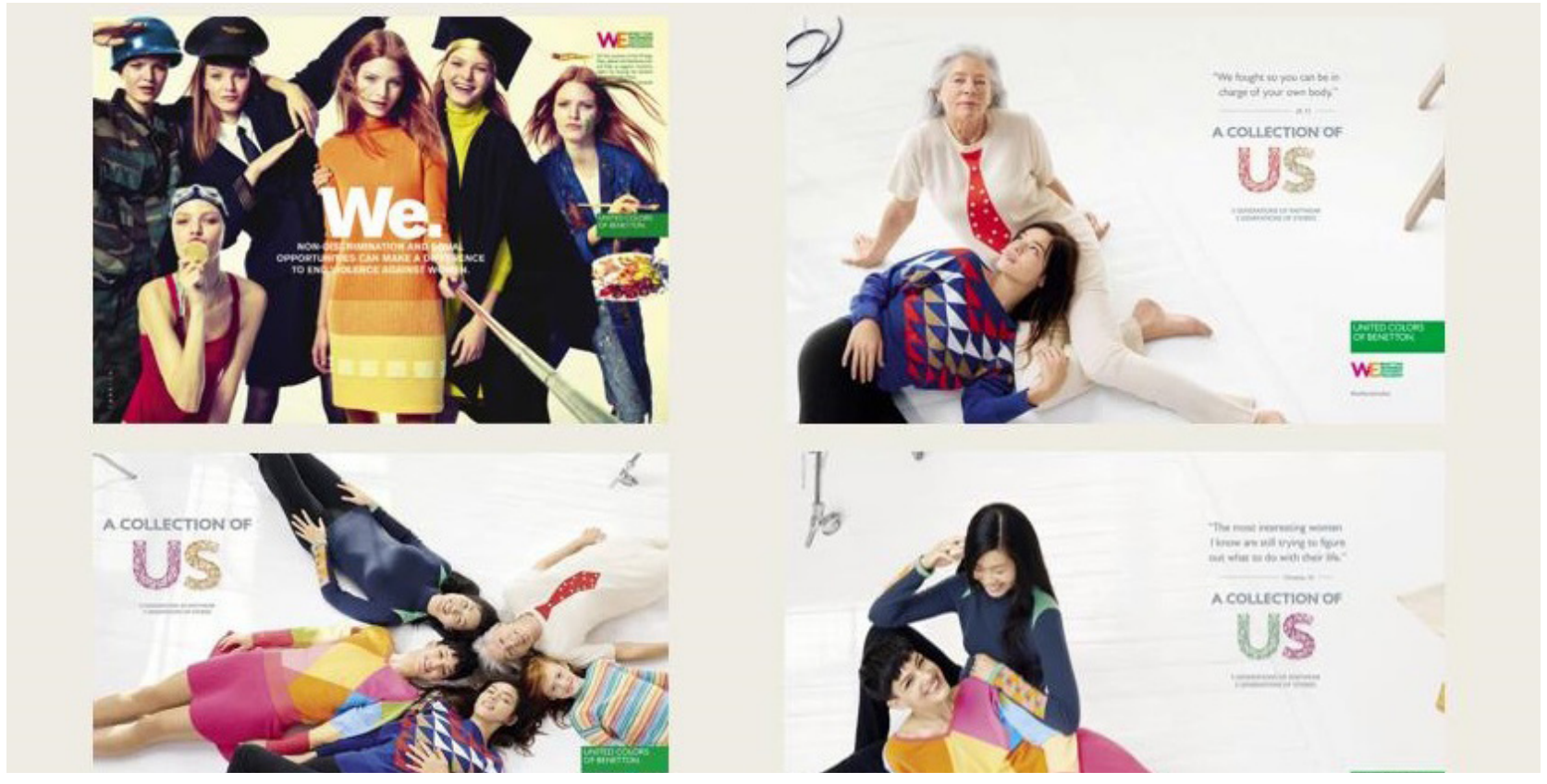

Рисунок 4. Рекламная кампания капсульной коллекции ACollectionofUs. Picture 4. The ad campaign for the capsule collection ACollectionofUs.

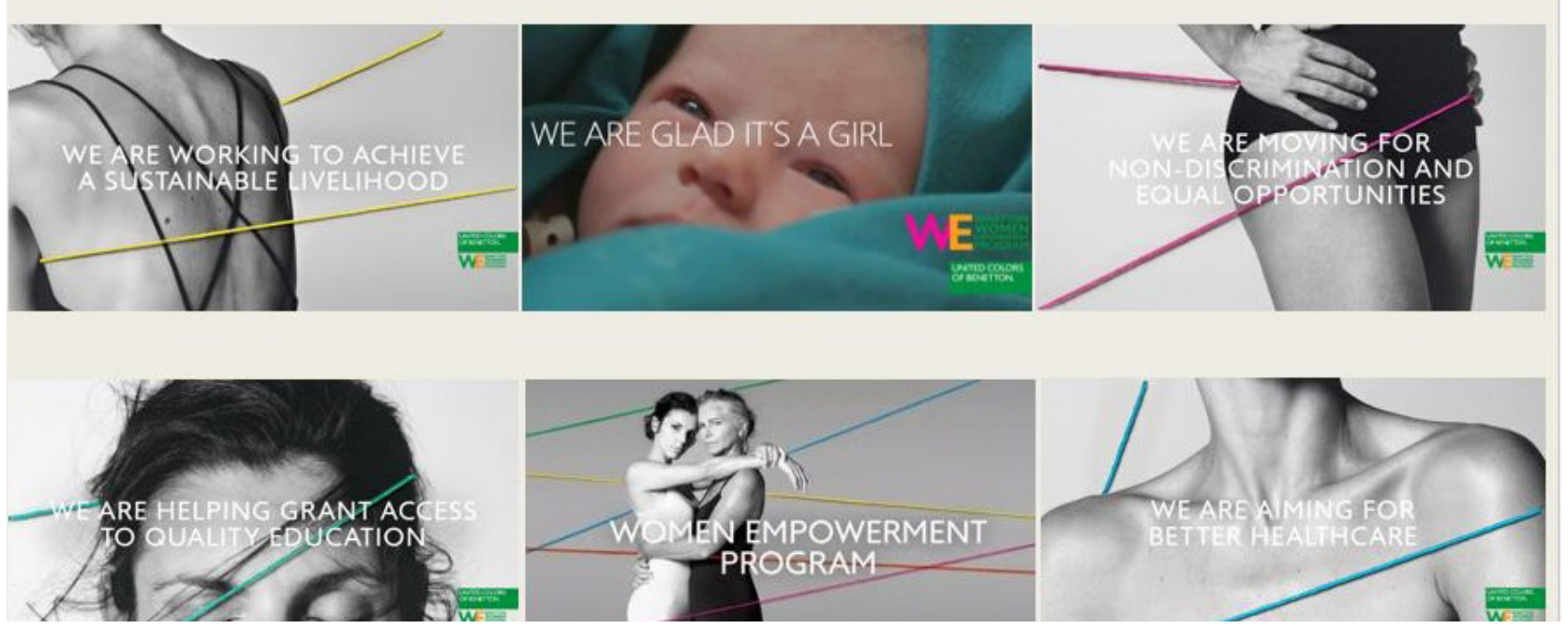

Рисунок 5. Снимки, сопровождающие социальную кампанию «WomenEmpowerment».

Picture 5. Photographs made for the "WomenEmpowerment" social campaign. 
Одновременно с данным социальным проектом бренд представил капсульную коллекцию A CollectionOfUs, связанную с переосмыслением достижений и открытий за всю историю марки. В качестве моделей были представительницы женского пола разных возрастов и рас (рис. 4). Сама социальная программа также сопровождалась рекламной кампанией (рис. 5).

В 1994 г. основателем BenettonGroup Лучано Бенеттоном был создан центр исследования коммуникаций Fabrica. Он представляет собой креативную лабораторию, бесплатное годовое обучение в которой, а также проживание и стипендию, могут получить молодые люди до 25 лет, проект которых прошел конкурсный отбор. На протяжении 12 месяцев студенты имеют возможность разрабатывать индивидуальные или коллективные проекты, проводить социальные исследования, делиться своими идеями с другими «фабрикантами» из других стран, что позволяет ощутимо расширить границы восприятия и посмотреть на привычные вещи иначе. За ходом проектов, которые разрабатывают молодые люди, постоянно следит команда научных руководителей, которые помогают развить идею и вдохновляют на поиск новых нестандартных решений. Fabrica максимально поддерживает и реализует межкультурный обмен между студентами и преподавателями, организовывая вечерние лекции, открытые форумы и воркшопы с всемирно известными социологами, историками, художниками, дизайнерами. Центр оснащен суперсовременным технологическим оборудованием, его библиотека насчитывает более 5000 книг о дизайне, искусстве, фотографии и других областях визуальной коммуникации.

Таким образом, своими социальными кампаниями бренд United colors of Benetton участвует в решении проблем молодежной безработицы и ущемления прав женщин по всему миру, пропагандируя социальные нормы равноправия женщин и мужчин.

Социальные кампании бренда Zara. Аналогично бренду H\&M, Zara занимается сбором ненужной поношенной одежды для дальнейшей вторичной переработки ${ }^{1}$. Вся одежда, которая собирается через сеть магазинов, передается в некоммерческие организации, где происходит сортировка в целях обеспечения оптимального использования. Организации Красный крест, Дом дружбы, Армия спасения, Caritas, Redress, Eden, La relais, Fabric Republic передают подержанную одежду тем, кто в ней нуждается, обеспечивают ее вторичную переработку и использование для производства новых тканей, либо осуществляют ее продажу через благотворительные каналы с целью финансирования своих социальных проектов. В настоящее время техноло-

${ }^{1}$ Zara [Электронный ресурс] // Zara. URL: https://www.zara.com/ru/ru/ustoychivoyerazvitiye-sbor-odezhdy-l1452 (дата обращения 11.01.2019). 
Научные труды Московского гуманитарного университета 2019 № 5

гии позволяют осуществлять вторичную переработку только одежды из $100 \%$ хлопка, шерсти или полиэстера. Поэтому Zara активно участвует в исследовательских проектах, которые в будущем обеспечат возможность переработки других видов тканей.

C 2011 г. компания сотрудничает с Entreculturas в 11 странах Африки, Азии и Америки, реализующей программы по профессионально - техническому образованию для социально уязвимых групп населения, и прежде всего - молодежи. В сфере образования ведется совместная работа со многими университетами для развития социальных и социологических исследований.

Также бренд Zara имеет линейку одежды, модели которой производятся с использованием лучших процессов пошива одежды и наиболее экологически устойчивого сырья. Одежда из данной линейки отмечена особой этикеткой JoinLife с разделением на 3 вида:

- Careforfiber. Данной этикеткой отмечены все товары, которые были произведены из экологически устойчивого сырья, такого как органический хлопок, ТЕНСЕЛ Лайоцелл или переработанные волокна;

- Careforwater. Этикетка отличает товары, произведенные с использованием технологии, направленной на экономное потребление воды;

- Careforplanet. Указывает какие изделия были произведены с использованием процессов, позволяющих сократить вредные выбросы.

Zara позиционирует себя как бренд, не использующий в производстве кожу и другие продукты животного происхождения, забой которых производится исключительно для коммерческого использования их шкур, раковин, рогов, костей, перьев, пуха или любых других материалов, а также не реализует косметику, тестируемую на животных. Также компания принимает участие в программе FurFreeRetailer, реализуемой FurFreeAlliance, поэтому не использует натуральный мех в своей продукции. Таким образом, бренд большое внимание уделяет таким вопросам, как экономное использование электроэнергии, переработка и повторное использование ненужной одежды, тем самым формируя ценности и нормы экологической культуры молодежи.

Анализ социальных проектов, социальных кампаний молодежных брендов одежды H\&M, United colors of Benetton, Zara показал, что они принимают участие в решении таких актуальных социальных проблем, как сохранение природных ресурсов, минимизация отходов потребления, молодежная безработица, дискриминация женщин, взаимодействие людей старшего и младшего поколений и др. Предлагая конкретные способы решения проблем, данные организации высказывают свое отношение к ним, тем самым определяя социальные ценности и нормы. Наибольший акцент дела- 
ется на формирование ценностей и норм экологической культуры молодежи. Презентация одежды, ее продвижение на рынке происходит не только открыто в рекламных кампаниях, но и через отношение к актуальным социальным проблемам. Именно это и позволило рассмотреть молодежные бренды одежды в качестве агентов социализации.

\section{СПИСОК ЛИТЕРАТУРЫ}

Агранат, Д. Л., Васильева, Н. В., Гневашева, В. А., Ковалева, А. И., Луков, В. А., Селиверстова, Н. А. (2005) Трудовая социализация подростков. М.: Издво Моск. гуманит. ун-та. 64 с.

Ковалева, А. И. (1997) Социализационная норма в современном российском обществе : автореф. дис. ... д-ра социол. наук. М. 32 с.

Ковалева, А.И. (1998) Социализационные траектории современной российской молодежи // Молодежь и общество на рубеже веков. Международная научно-практическая конференция. М. : Социум. С. 78-83.

Ковалева, А. И. (2000) Социализационные условия идентификации // Социологический сборник. М. : Социум. С. 3-7.

Ковалева, А. И. Социализация молодежи [Электронный ресурс] // Coциология молодежи. Энциклопедия. URL: http://soc-mol.ru/encyclopaedia/ theories/185-socializaciya-molodezhi.html (дата обращения 02.04.2019).

Луков, В. А. (2012) Теории молодежи: междисциплинарный анализ. М.: Канон+ ; РООИ «Реабилитация». 528 с.

Перинская, Н. А. (2014) Особенности профессиональной социализации // Высшее образование для XXI в.: XI Международная научная конференция. Москва, 27-29 ноября 2014 г.: Доклады и материалы. Секция 2. Социология образования / отв. ред. Н.А. Селиверстова. М. : Изд-во Москов.гуманит.ун-та. 107 c. С. $56-60$.

Селиверстова, Н. А. (1993) Особенности социализации детей в иноэтнической среде (на примере русских в Узбекистане) : автореф. дис.... канд. соц. наук. М. 25 c.

Селиверстова, Н. А. (1994) Дети русских старожилов в Узбекистане (к проблеме социализации в иноэтнической среде) // Восток. Афро-азиатские общества: история и современность. № 2. С. 62-70.

Селиверстова, Н. А. (2017) Факторы профессиональной социализации выпускников социологических факультетов // Высшее образование для XXI в.: проблемы воспитания. XIV Международная научная конференция : в 2-х частях. М. : Изд-во Москов. гуманит. ун-та. Ч. 1. С. 189-194.

Дата поступления: 15.09.2019 г. 
Калуга Марина Сергеевна - студентка 5 курса направления «Социология» факультета психологии, педагогики и социологии Московского гуманитарного университета. Адрес: 111395, Россия, г. Москва, ул. Юности, д. 5. Эл. адрес: nata961970@mail.ru. Научный руководитель — д-р социол. н., проф. Н. А. Селиверстова.

Kaluga Marina Sergeyevna, 5th year Student, academic programme "Sociology", Moscow University for the Humanities. Postal address: 5, Yunosti St., Moscow, Russian Federation, 111395. E-mail: nata961970@mail.ru. Scientific Adviser - N. A. Seliverstova, Doctor of Sociology, Professor.

\section{Для цитирования:}

Калуга М. С. Молодежные бренды одежды как агенты социализации [Электронный ресурс] // Научные труды Московского гуманитарного университета. 2019. № 5. URL: http://journals.mosgu.ru/trudy/article/view/1053 (дата обращения: дд.мм.гг.). DOI: 10.17805/trudy.2019.5.4 